\title{
Correlation between maximum crystal growth rate and glass transition temperature of silicate glasses
}

\author{
Vladimir M. Fokin, Marcio L.F. Nascimento *, Edgar D. Zanotto * \\ Vitreous Materials Laboratory, LaMaV-UFSCar, 13565-905, São Carlos-SP, Brazil
}

Received 11 May 2004; received in revised form 9 February 2005

\begin{abstract}
Recent publications demonstrate that the maximum homogeneous nucleation rates, $I_{\max }$, of silicate glasses strongly diminish with the reduced glass transition temperature, $T_{\mathrm{gr}}\left(=T_{\mathrm{g}} / T_{\mathrm{m} / \mathrm{L}}\right.$, where $T_{\mathrm{g}}$ is the glass transition temperature and $T_{\mathrm{m} / \mathrm{L}}$ is the melting point or liquidus temperature). In addition, the critical cooling rates for metallic glass formation, $R_{\mathrm{c}}$, also drop with rising $T_{\mathrm{gr}}$. From these empirical observations as well as from theoretical considerations, it is expected that the maximum crystal growth rates, $U_{\text {max }}$, also depend on $T_{\mathrm{gr}}$. In this paper we test and confirm this assumption by plotting experimental $U_{\max }$ vs. $T_{\mathrm{gr}}$ for 20 silicate glasses, and then use the most common crystal growth model - screw dislocation growth - to calculate and compare maximum experimental growth rates with theoretical predictions. Despite several assumptions made for the calculations, there is good agreement between theory and experiment, both in the magnitude of $U_{\max }\left(T_{\mathrm{gr}}\right)$ and in the temperature of the maximum crystal growth rate, $T_{\max }^{U}$. These findings indicate that the screw dislocation growth model is a good approximation to describe crystal growth in silicate glasses.
\end{abstract}

(C) 2005 Elsevier B.V. All rights reserved.

\section{Introduction}

Fundamental studies of the mechanisms and kinetics of crystal nucleation and growth in glass-forming liquids not only provide valuable scientific insight, but also have practical relevance. Indeed, a plethora of novel oxide, chalcogenide and metallic glasses, as well as micro and nanostructured glass-ceramics, are being continuously developed based on such knowledge [1-5].

In a recent publication [6] we demonstrated that the maximum nucleation rates, $I_{\max }$, of silicate glasses strongly diminish with reduced glass transition temperature, $T_{\mathrm{gr}}=T_{\mathrm{g}} / T_{\mathrm{m} / \mathrm{L}}$, where $T_{\mathrm{g}}$ is the glass transition temperature (measured by conventional methods) and $T_{\mathrm{m} / \mathrm{L}}$

\footnotetext{
${ }^{*}$ Corresponding authors.

E-mail addresses: pmlfn@iris.ufscar.br (M.L.F. Nascimento), dedz@power.ufscar.br (E.D. Zanotto).

URL: http://www.lamav.ufscar.br (Vitreous Materials Lab.).
}

is the melting point or liquidus temperature. In Ref. [6] we showed, for 51 glass-forming liquids, that the experimental $I_{\max }$ drops by 12 orders of magnitude, from about $10^{14}$ to $10^{2} \mathrm{~m}^{-3} \mathrm{~s}^{-1}$, when $T_{\mathrm{gr}}$ varies from 0.50 to 0.58 . To confirm this trend, we show Fig. 1, an expanded version of Fig. 1 of Ref. [6], now with 55 glasses. The highest nucleation rate (about $10^{18} \mathrm{~m}^{-3} \mathrm{~s}^{-1}$ ) was estimated for a lithium silicate glass with $44 \mathrm{~mol} \%$ of lithium oxide via X-ray diffraction line broadening of a fully crystallized sample [7]. Thus, the range of variation of the nucleation rate with $T_{\mathrm{gr}}$ now extends to about 16 orders of magnitude.

In addition, Lu et al. [8] demonstrated that the critical cooling rates for metallic glass formation, $R_{\mathrm{c}}$, drop from $10^{10}$ to $10^{-4} \mathrm{~K} / \mathrm{s}$ when $T_{\mathrm{gr}}$ varies from 0.25 to 0.70 . Since $R_{\mathrm{c}}$ is directly linked to both homogeneous nucleation rates $I(T)$ and growth rates $U(T)\left[R_{\mathrm{c}} \sim T_{\mathrm{L}} \cdot I_{\mathrm{n}}^{1 / 4} \cdot U_{\mathrm{n}}^{3 / 4}\right.$, where $T_{\mathrm{L}}$ is the liquidus temperature, and $I_{\mathrm{n}}$ and $U_{\mathrm{n}}$ refer to the nucleation and growth rates at the nose of the corresponding transformation-temperature-time curve 


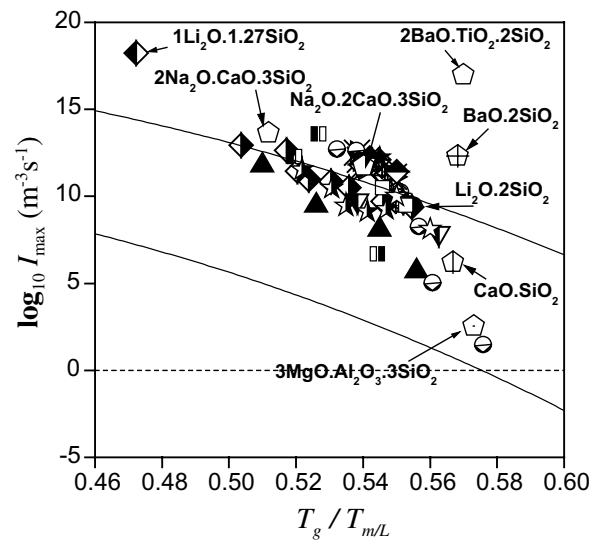

Fig. 1. Maximum nucleation rates vs. $T_{\mathrm{gr}}$ for 55 silicate glasses of stoichiometric and non-stoichiometric compositions. Lines were calculated from CNT with different thermodynamic barriers (see Ref. [6]).

of the glass], it is reasonable to expect that the maximum crystal growth rates $U_{\max }=U\left(T_{\max }^{U}\right)$ also depend on $T_{\mathrm{gr}}$. This dependence of $U_{\max }$ is also expected from theoretical considerations, since the kinetic barriers for nucleation and growth should be similar. In this paper we test and confirm this hypothesis by plotting experimental $U_{\max }$ vs. $T_{\mathrm{gr}}$ for 20 silicate glasses. We then use the most common crystal growth model - screw dislocation growth - to calculate and compare maximum experimental growth rates and their temperatures, $T_{\max }^{U}$, with theoretical predictions.

\section{Experimental data}

Figs. 2 and 3 show literature data for $U_{\max }$ and $T_{\max }^{U}$ (collected in Table 1) for 20 silicate glasses, respectively,

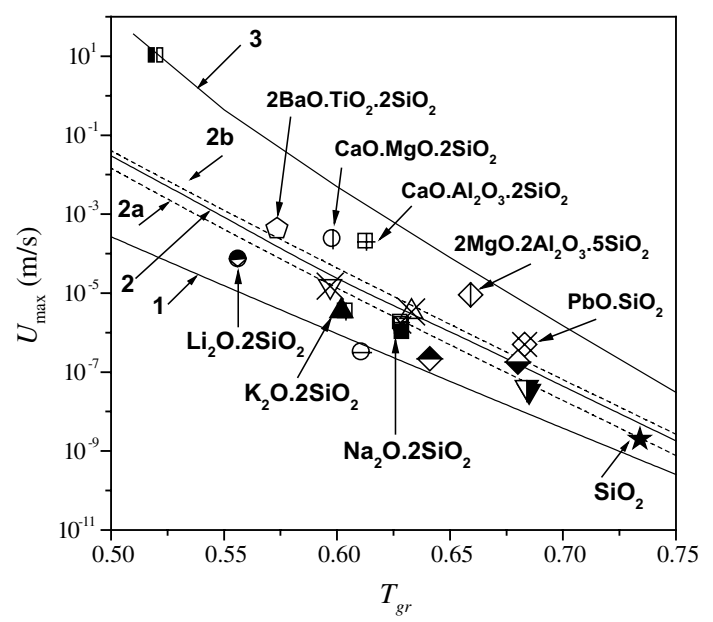

Fig. 2. Experimental data points for 20 silicate glasses, and calculated curves for $U_{\max }$ vs. $T_{\mathrm{gr}}$ (see also Table 1). Curves $(1,2,3)$ : fixed reduced melting entropy $\Delta S_{\mathrm{r}}=5$ and varied $T_{0 \mathrm{r}}=0.3$ (1); 0.4 (2); 0.5 (3). Curves $(2 \mathrm{a}, 2 \mathrm{~b})$ : fixed $T_{0 \mathrm{r}}=0.4$ and varied melting entropy $\Delta S_{\mathrm{r}}=2$ (2a); 8 (2b).

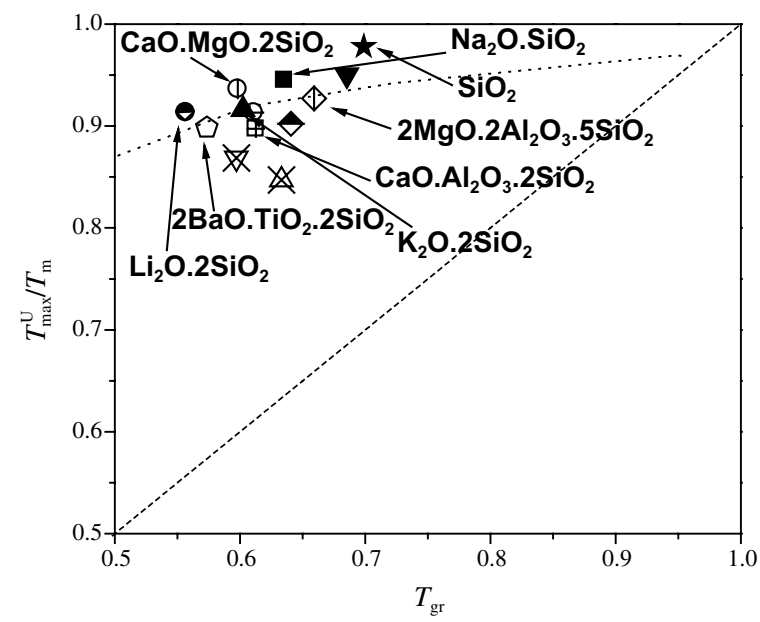

Fig. 3. Temperatures of maximum growth rate vs. reduced glass transition temperature for 16 silicate glasses. Dashed lines refer to the case of $T_{\max } / T_{\mathrm{m}}=T_{\mathrm{gr}}$. Dotted lines are calculated with $\Delta S_{\mathrm{r}}=5$ and $T_{0 \mathrm{r}}=0.4$.

as a function of $T_{\mathrm{gr}}$. The values of $T_{\mathrm{g}}$ were measured by DSC or calculated as the temperature where the viscosity is $10^{12} \mathrm{~Pa} \mathrm{~s}$.

The maximum growth rates, $U_{\max }$, drop by about 10 orders of magnitude for silicate glasses having $T_{\mathrm{gr}}$ from 0.52 to 0.73 , showing a well-defined tendency. The calculated lines shown in Figs. 2 and 3 will be discussed below.

\section{Theory}

\subsection{Brief review of the main crystal growth models}

For stoichiometric glass compositions that do not undergo compositional changes during crystallization, i.e., polymorphic crystallization, long-range diffusion is not necessary for crystal growth; thus, interfacial rearrangements are likely to control the crystal growth process. In this case, the focus of theoretical treatments has been directed at the nature of the interface. Three standard models are used to describe the crystal growth process in glasses, which are based on different views of the nature of the crystal/liquid interface. These models are: (i) the screw dislocation model; (ii) the normal or continuous growth model; and (iii) the two-dimensional surface nucleation growth. All these models are based on the assumption that the release of latent heat does not substantially alter the crystal-melt interface temperature. The two most common models for oxide liquids, (i) and (ii), are summarized in the following paragraphs.

\section{(i) The screw dislocation growth model}

The screw dislocation growth model views the interface as smooth but imperfect on an atomic scale, with growth taking place at step sites provided by screw dis- 
Table 1

Experimental maximum growth rate, $U_{\max }$, corresponding temperature, $T_{\max }$, glass transition temperature, $T_{\mathrm{g}}$, and melting or liquidus temperature, $T_{\mathrm{m}}$, for the silicate systems used in this paper

\begin{tabular}{|c|c|c|c|c|c|c|}
\hline Glass & $T_{\mathrm{g}}(\mathrm{K})$ & $T_{\mathrm{m}}(\mathrm{K})$ & $T_{\mathrm{g}} / T_{\mathrm{m}}(\mathrm{K} / \mathrm{K})$ & $U_{\max }(\mathrm{m} / \mathrm{s})$ & $T_{\max }^{U}(\mathrm{~K})$ & Ref. \\
\hline $\mathrm{Li}_{2} \mathrm{O} \cdot 2 \mathrm{SiO}_{2}$ & 727 & 1306 & 0.557 & $7 \times 10^{-5}$ & 1193 & {$[15]$} \\
\hline $\mathrm{Na}_{2} \mathrm{O} \cdot 2 \mathrm{SiO}_{2}$ & 728 & 1146 & 0.635 & $1 \times 10^{-6}$ & 1083 & {$[16]$} \\
\hline Diopside $\left(\mathrm{CaO} \cdot \mathrm{MgO} \cdot 2 \mathrm{SiO}_{2}\right)$ & 996 & 1665 & 0.598 & $2.3 \times 10^{-4}$ & $\approx 1159$ & {$[17]$} \\
\hline Fresnoite $\left(2 \mathrm{BaO} \cdot \mathrm{TiO}_{2} \cdot 2 \mathrm{SiO}_{2}\right)$ & 983 & 1714 & 0.574 & $4.3 \times 10^{-4}$ & $\approx 1540$ & [18] \\
\hline Cordierite $\left(2 \mathrm{MgO} \cdot 2 \mathrm{Al}_{2} \mathrm{O}_{3} \cdot 5 \mathrm{SiO}_{2}\right)$ & 1083 & 1643 & 0.659 & $9 \times 10^{-6}$ & 1523 & [19] \\
\hline $\mathrm{SiO}_{2}$ & $1393[\log \eta=12]$ & 1993 & 0.7 & $2 \times 10^{-9}$ & 1949 & [20] \\
\hline $\mathrm{K}_{2} \mathrm{O} \cdot 2 \mathrm{SiO}_{2}$ & 791 & 1313 & 0.602 & $3.5 \times 10^{-6}$ & 1203 & {$[21]$} \\
\hline Anorthite $\left(\mathrm{CaO} \cdot \mathrm{Al}_{2} \mathrm{O}_{3} \cdot 2 \mathrm{SiO}_{2}\right)$ & 1123 & 1833 & 0.613 & $2 \times 10^{-4}$ & 1645 & {$[22]$} \\
\hline $\mathrm{Na}_{2} \mathrm{O} \cdot 3 \mathrm{SiO}_{2}$ & 743 & 1084 & 0.685 & $3.33 \times 10^{-8}$ & 1030 & {$[23]$} \\
\hline $4 \mathrm{~K}_{2} \mathrm{O} \cdot \mathrm{CaO} \cdot 20 \mathrm{SiO}_{2}$ & 745 & 1219 & 0.611 & $3.1 \times 10^{-7}$ & 1113 & {$[24]$} \\
\hline $\mathrm{Li}_{2} \mathrm{O} \cdot 3 \mathrm{SiO}_{2}$ & 734 & 1010 & 0.727 & $6.6 \times 10^{-5}$ & 1223 & {$[25]$} \\
\hline Luna 24 Mare & 923 & 1458 & 0.633 & $3.33 \times 10^{-6}$ & 1235 & {$[26]$} \\
\hline Luna 24 Highland & 978 & 1638 & 0.597 & $1.5 \times 10^{-5}$ & 1423 & [26] \\
\hline G-60 silicate glass & 918 & 1433 & 0.641 & $2.17 \times 10^{-7}$ & 1293 & {$[27]$} \\
\hline $\mathrm{PbO} \cdot \mathrm{SiO}_{2}$ & 708 & 1037 & 0.683 & $5 \times 10^{-7}$ & 934 & {$[28]$} \\
\hline Soda-lime-silica & 873 & 1283 & 0.68 & $1.8 \times 10^{-7}$ & 1228 & [29] \\
\hline Eucriptyte & 860 & 1653 & 0.520 & $1 \times 10^{1}(*)$ & $\approx 1488$ & {$[30]$} \\
\hline $33.6 \mathrm{Na}_{2} \mathrm{O} \cdot 66.4 \mathrm{SiO}_{2}$ & 721 & 1147 & 0.6284 & $1.78 \times 10^{-6}$ & 1030 & {$[23]$} \\
\hline $36 \mathrm{Na}_{2} \mathrm{O} \cdot 64 \mathrm{SiO}_{2}$ & 720 & 1145 & 0.629 & $1.58 \times 10^{-6}$ & 1040 & {$[23]$} \\
\hline $39.1 \mathrm{Na}_{2} \mathrm{O} \cdot 60.9 \mathrm{SiO}_{2}$ & 714 & 1183 & 0.604 & $3.38 \times 10^{-6}$ & 1038 & [23] \\
\hline
\end{tabular}

$T_{\mathrm{g}}$ and $T_{\mathrm{m}}$ were measured by DSC or were obtained from the Sciglass ${ }^{\circledR}$ database [31]. $T_{\mathrm{g}}$ of $\mathrm{SiO}_{2}$ glass was obtained from viscosity data. G-60 glass composition: $57.92 \mathrm{SiO}_{2}+20.08 \mathrm{CaO}+6.93 \mathrm{Al}_{2} \mathrm{O}_{3}+5.24 \mathrm{Na}_{2} \mathrm{O}+3.53 \mathrm{MgO}+1.65 \mathrm{Fe}_{2} \mathrm{O}_{3}+1.10 \mathrm{TiO}_{2}+0.79 \mathrm{ZnO}+0.39 \mathrm{~K}_{2} \mathrm{O}+0.11 \mathrm{BaO}+$ $0.07 \mathrm{PbO}+0.06 \mathrm{Cr}_{2} \mathrm{O}_{3}+0.03 \mathrm{CuO}+0.01 \mathrm{CdO}+0.01 \mathrm{NiO}(\mathrm{wt} \%)$. Luna 24 Mare basalt glass composition: $46.26 \mathrm{SiO}_{2}+20.00 \mathrm{FeO}+12.98 \mathrm{Al}_{2} \mathrm{O}_{3}+$ $12.73 \mathrm{CaO}+6.47 \mathrm{MgO}+0.98 \mathrm{TiO}_{2}+0.29 \mathrm{Na}_{2} \mathrm{O}+0.04 \mathrm{~K}_{2} \mathrm{O} \quad(\mathrm{wt} \%)$. Luna 24 Highland basalt glass composition: $44.97 \mathrm{SiO}_{2}+4.89 \mathrm{FeO}+$ $26.74 \mathrm{Al}_{2} \mathrm{O}_{3}+15.64 \mathrm{CaO}+6.86 \mathrm{MgO}+0.30 \mathrm{TiO}_{2}+0.23 \mathrm{Na}_{2} \mathrm{O}+0.05 \mathrm{~K}_{2} \mathrm{O} \quad(\mathrm{wt} \%)$. Soda-lime-silica glass: $\quad 72 \mathrm{SiO}_{2}+16 \mathrm{Na}_{2} \mathrm{O}+12 \mathrm{CaO} \quad$ wt $\%$. $\quad(*)$ Estimate.

locations intersecting the interface. The crystal growth rate $U$ is given by [9]:

$U=f v \lambda\left[1-\exp \left(-\frac{\Delta G}{R T}\right)\right]$,

$v=v_{0} \exp \left(-\frac{\Delta G_{\mathrm{D}}}{R T}\right)$,

where $v$ is the frequency of atomic jumps at the interface, $v_{0}$ is the vibrational frequency of the growth controlling atoms, $\Delta G_{\mathrm{D}}-$ the activation free energy for diffusion across the interface, $\lambda$ - the distance advanced by the interface in an unit kinetic process (usually taken as a molecular diameter), $\Delta G$ - the thermodynamic driving force for crystallization, i.e., the difference between the free energies of the undercooled melt and crystalline phase per mole, $T$ - the absolute temperature, and $R-$ the gas constant. The fraction of sites on the interface where atoms can preferentially be added or removed, $f$, is given by

$f=\frac{\lambda \Delta G}{4 \pi \sigma V_{\mathrm{m}}} \approx \frac{\Delta T}{2 \pi T_{\mathrm{m}}}=\frac{\left(1-T_{\mathrm{r}}\right)}{2 \pi}$,

where $T_{\mathrm{r}} \equiv T / T_{\mathrm{m}}$

and $\sigma$ is the specific surface energy of the liquid/crystal interface, $V_{\mathrm{m}}$ is the molar volume of the crystal, $T_{\mathrm{m}}$ is the thermodynamic melting point, and $\Delta T=T_{\mathrm{m}}-T$ is the undercooling.
According to Ref. [9]

$\sigma=\alpha \Delta H_{\mathrm{m}} V_{\mathrm{m}}^{-2 / 3} N_{\mathrm{A}}^{-1 / 3}$,

where $N_{\mathrm{A}}$ is Avogadro's number and $\Delta H_{\mathrm{m}}$ is the melting enthalpy.

The fraction of preferred sites $f$ was calculated by Eq. (3) using the empirical coefficient $\alpha$ equal to 0.5 in Eqs. (4) and (5) for the thermodynamic driving force, $\Delta G$ - to be described latter in this article.

\section{(ii) Normal growth model}

In the framework of the normal (or continuous) growth model, the interface is pictured as rough on an atomic scale and all the sites on the interface are assumed to be equivalent growth sites $(f \approx 1)$. The growth rate is expressed by Eq. (1) with $f=1$.

\section{(iii) Jackson's model for the interface}

Jackson [10] proposed a successful approach based on a consideration of the interface morphology and on the entropy of fusion, $\Delta S_{\mathrm{m}}$. In his model, materials with small entropies of fusion $\left(\Delta S_{\mathrm{m}}<2 R\right)$, such as $\mathrm{GeO}_{2}$ and $\mathrm{SiO}_{2}$, crystallize with non-faceted morphologies and exhibit interface site factors - which are independent of undercoolings and kinetics - of the form predicted by the normal growth model. In contrast, materials with large entropies of fusion $\left(\Delta S_{\mathrm{m}}>4 R\right)$, such as most oxide crystals, crystallize with faceted morphologies and exhibit interface site factors that increase with undercooling. 


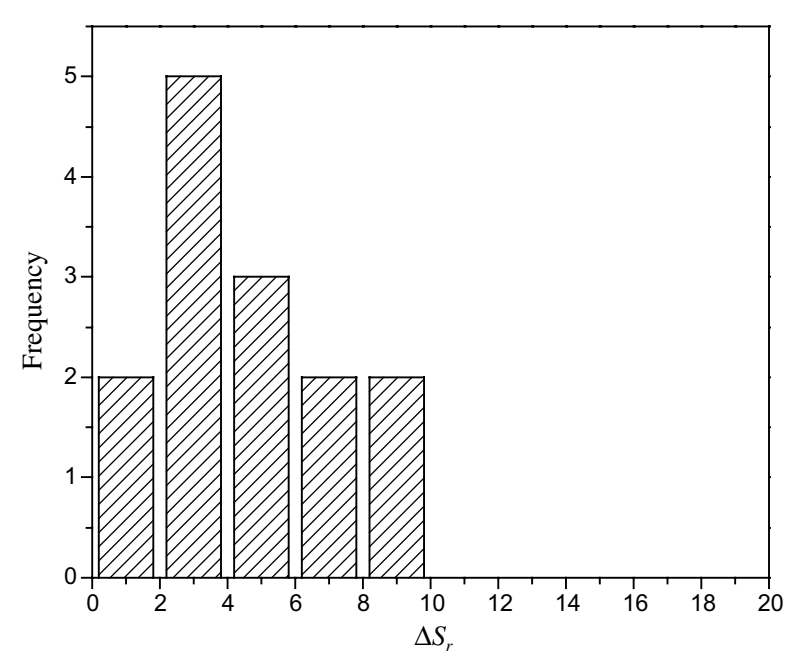

Fig. 4. Frequency distribution of reduced melting entropy in 14 silicate glasses with average value of $\Delta S_{\mathrm{r}}=5 \pm 3$.

In that case, two-dimensional surface nucleation or screw dislocation growth should be observed, but this last is the most likely mechanism. Since most silicate crystals have $\Delta S_{\mathrm{m}}>4 R$ (see Fig. 4), hereinafter we will consider screw dislocation growth (except for pure silica glass).

\subsection{Governing parameters and calculations}

Regardless of the assumed growth mechanism to analyze or calculate crystal growth kinetics, one must know the thermodynamic driving force, $\Delta G$, and the activation free energy for diffusion across the crystal-liquid interface, $\Delta G_{\mathrm{D}}$. In this article we use the following approximations to estimate these quantities.

\subsubsection{Thermodynamic driving force}

Neglecting the differences in specific heats between the crystalline and liquid phases, we express $\Delta G$ via Eq. (5):

$\Delta G=\Delta H_{\mathrm{m}}\left(1-T_{\mathrm{r}}\right)$,

Eq. (5) can be rewritten in terms of the 'reduced melting entropy', $\Delta S_{\mathrm{r}} \equiv S_{\mathrm{m}} / R$, as

$\frac{\Delta G}{R T}=\frac{\Delta H_{\mathrm{m}}}{R T_{\mathrm{m}}}\left(\frac{1}{T_{\mathrm{r}}}-1\right)=\Delta S_{\mathrm{r}}\left(\frac{1}{T_{\mathrm{r}}}-1\right)$.

Based on literature data for 14 silicates glasses, the histogram of Fig. 4 show that the reduced melting entropy $\Delta S_{\mathrm{r}}$ typically varies from 2 to 10 .

\subsubsection{Frequency of atomic jumps at the interface}

Assuming that the molecular motion required for crystal growth is similar to that involved in transport in the bulk liquid, the jump frequency factor, $v$, can be represented through the Stokes-Einstein equation
$v=\frac{k_{\mathrm{B}} T}{3 \pi \lambda^{3} \eta}$,

where $\eta$ is the shear viscosity, $k_{\mathrm{B}}$ is the Boltzmann constant, and $\lambda$ is the jump distance.

Thus, following several authors (e.g., [11]), we assume that the activation free-energy for molecular transport across the crystal/liquid interface, $\Delta G_{\mathrm{D}}$, is equal to the activation free energy for viscous flow, $\Delta G_{\eta}$,

$\Delta G_{\mathrm{D}}=\Delta G_{\eta}$.

Since the crystal growth rate maximum is located at temperatures well above $T_{\mathrm{g}}$, the Stokes-Einstein equation is valid and Eqs. (6) and (7) are thus good approximations.

The viscosities of most silicate melts are well described by the empirical equation of Vogel-FulcherTammann (VFT):

$\log \eta=A+\frac{B}{T-T_{0}}$

where $A, B$ and $T_{0}$ (the Kauzmann temperature) are empirical parameters. It is possible to show that the VFT equation corresponds to a temperature-dependent activation free energy, $\Delta G_{\eta}(T)$, of the following form [12]:

$$
\begin{aligned}
& \eta=\eta_{0} \exp \left(\frac{\Delta G_{\eta}(T)}{R T}\right), \\
& \log \eta_{0}=A ; \\
& \frac{\Delta G_{\eta}}{R T}=\frac{C}{T_{\mathrm{r}}-T_{0 \mathrm{r}}} ; \\
& C \equiv \frac{2.30 B}{T_{\mathrm{m}}} ; \quad T_{0 \mathrm{r}} \equiv T_{0} / T_{\mathrm{m}} .
\end{aligned}
$$

From literature data for 13 silicate glasses, the frequency distribution of Fig. 5 show that the Kauzmann temper-

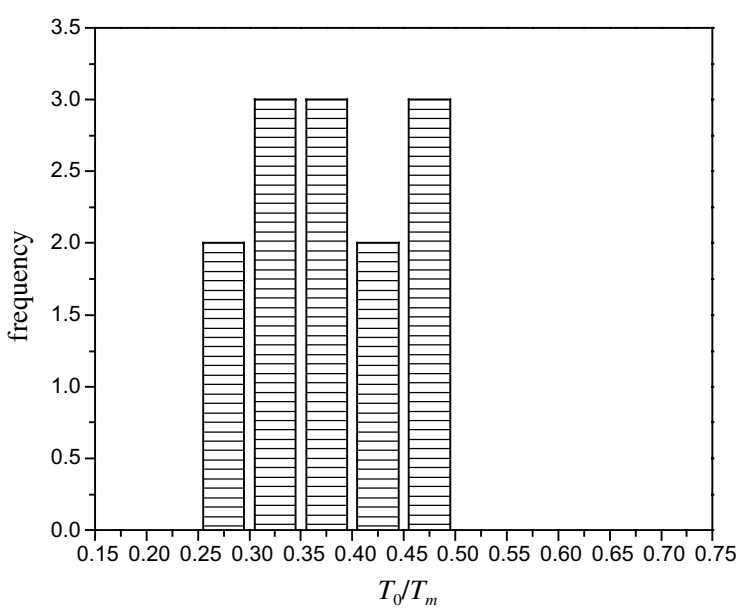

Fig. 5. Frequency distribution of $T_{0} / T_{\mathrm{m}}$ for 13 silicate glasses. Average value is $0.39 \pm 0.06$. 


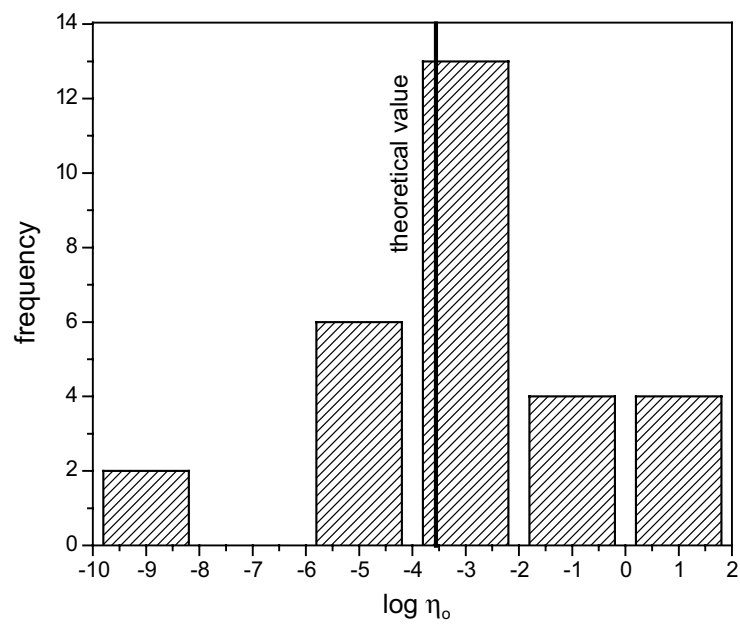

Fig. 6. Frequency distribution of $A=\log \eta_{0}$ for 29 silicate glasses. Average value of $A=-3.5 \pm 2.0$.

ature, $T_{0 \mathrm{r}}$, varies from about 0.3 to 0.5 . On the other hand, using literature data for 29 silicate glasses, Fig. 6 shows that the most frequent value of $A=\log \left(\eta_{0}\right.$, $\mathrm{Pa} \mathrm{s}$ ) is about -3.4 . It should be emphasized that the parameters of the VFT equation presented in Figs. 5 and 6 correspond to a wide temperature range, from about $T_{\mathrm{g}}$ to temperatures above $T_{\mathrm{m}}$.

The empirical, average value of $A$ is close to the theoretical value estimated via Eq. (10), which was derived in Ref. [13]:

$\eta_{0}=\frac{k_{\mathrm{B}} T}{\lambda^{3}} \tau_{0}$,

where $\tau_{0}=h / k_{\mathrm{B}} T$ is a characteristic time of the order of the period of atomic vibrations, $h$ is Planck's constant, and $\lambda$ has a value of the order of $\mathrm{Si}-\mathrm{O}$ bond length. Using $\lambda=1.86 \AA$ we obtain $\log \left(\eta_{0}, \mathrm{~Pa} s\right)=-4$.

Taking into account that $\eta\left(T_{\mathrm{g}}\right) \cong 10^{12} \mathrm{~Pa}$ s and using the average value of $\eta_{0}$, we estimate that $\Delta G_{\eta}\left(T_{\mathrm{g}}\right) / R T_{\mathrm{g}}$ from Eq. (9) is about 35 for silicate glasses.

The determination of parameter $C$ in Eq. (9) [via Eq. (11)] meets the condition that $\eta=10^{12} \mathrm{~Pa}$ s at $T_{\mathrm{r}}=T_{\mathrm{gr}}$.

$C=C^{\prime}\left(T_{\mathrm{gr}}-T_{0 \mathrm{r}}\right) ; \quad C^{\prime} \equiv \frac{\Delta G_{\eta}\left(T_{\mathrm{g}}\right)}{R T_{\mathrm{g}}}$.

Hence, one can use Eq. (11) to model glass viscosity (and $\Delta G_{\mathrm{D}}$, see Eq. (7)) corresponding to given values of $T_{\mathrm{gr}}$ at fixed $T_{0 \mathrm{r}}$.

Within reasonable limits of $T_{0 \mathrm{r}}$ and $\Delta S_{\mathrm{r}}$ shown in Figs. 5 and 4, we thus performed calculations of $U\left(T_{\mathrm{r}}\right)$ in wide temperature ranges, including the temperatures of the maximum, $T_{\max }^{U}$, for different values of reduced glass transition temperature via Eqs. (1), (3), (5a) and (11). We then took $U_{\max }$ and $T_{\max }^{U}$ from these $U\left(T_{\mathrm{r}}\right)$ curves and plotted these values as a function of $T_{\mathrm{gr}}$. The results of our computations of $U_{\max }$ and $T_{\max }^{U}$ are represented by lines in Figs. 2 and 3.

\section{Results}

Within the intrinsic approximations embedded in the above described equations, and using empirical bounds for the melting entropy (which determines the thermodynamic driving force) and for the Kauzmann temperature, $T_{0 \mathrm{r}}$, and viscosity pre-exponential, $\eta_{0}$, (which determine the diffusion process controlling crystal growth), one can estimate the predicted behavior of $U_{\max }$ and $T_{\max }^{U} / T_{\mathrm{m}}$ vs. $T_{\mathrm{gr}}$ for typical silicate melts.

The $U_{\max }$ curves are plotted in Fig. 2. Lines 1, 2 and 3 in Fig. 2 refer to calculations performed with Eqs. (1), (3), (5a) and (11) using the average $\Delta S_{\mathrm{r}}=5$ and variable $T_{0 \mathrm{r}}=0.3,0.4$ and 0.5 , respectively, for silicates. The predicted $U_{\max }$ increases by about one order of magnitude when $T_{0 \mathrm{r}}$ increases by 0.1 , while the predicted $U_{\max }$ is little sensitive to changes in $\Delta S_{\mathrm{r}}$ (in Fig. 2 see curves $2 \mathrm{a}, 2$ and $2 \mathrm{~b}$ for $\Delta S_{\mathrm{r}}=2,5$ and 8 , respectively).

At high temperatures, such as $T_{\max }^{U}$, one can expand Eq. (1) in Taylor series and rewrite it as

$$
\begin{aligned}
U & =f v_{0} \lambda \frac{\Delta G}{R T} \exp \left(-\frac{C^{\prime}\left(T_{\mathrm{gr}}-T_{0 \mathrm{r}}\right)}{T_{\mathrm{r}}-T_{0 \mathrm{r}}}\right) \\
& =f v_{0} \lambda \Delta S_{\mathrm{r}}\left(\frac{1}{T_{\mathrm{r}}}-1\right) \exp \left(-\frac{C^{\prime}\left(T_{\mathrm{gr}}-T_{0 \mathrm{r}}\right)}{T_{\mathrm{r}}-T_{0 \mathrm{r}}}\right) .
\end{aligned}
$$

According to this equation, $U$ (and $U_{\max }$ ) is much more sensitive to changes in $T_{0 \mathrm{r}}$ than in $\Delta S_{\mathrm{r}}$. For any set of parameters, $U_{\max }$ decreases with increasingly higher $T_{\mathrm{gr}}$; and the position of crystal growth maximum $\left(T_{\max }^{U}\right)$ shifts to $T_{\mathrm{m}}$. It is important to note that $T_{\max }^{U}$ approaches $T_{\mathrm{g}}$ (see Fig. 3). This behavior results in an increased viscosity at $T_{\max }$, which, together with a decrease in the thermodynamic driving force $\left(T_{\max }^{U}\right.$ tends $T_{\mathrm{m}}$ ), diminishes crystal growth in glasses with high $T_{\mathrm{gr}}$.

\section{Discussion}

Taking into account all the assumptions made above, it is somewhat surprising that there is good agreement between the experimental points and the calculated curves; not only in the dependence of $U_{\max }\left(T_{\mathrm{gr}}\right)$ but also in the magnitudes of $U_{\max }$. It should be emphasized, however, that quartz glass, in contrast to the other glasses, exhibits normal growth. However, calculations for normal growth differ very little from those for screw dislocation growth. The experimental points are connected by lines calculated with typical values of the parameters governing crystal growth. Their deviations from line 2 do not exceed 1.5 orders of magnitude (see Fig. 2). This result is better than the predictions of $I_{\max }\left(T_{\mathrm{gr}}\right)$ given in Ref. [6], which show a trend of $I_{\max }\left(T_{\mathrm{gr}}\right)$, but do not agree with the experimental data in absolute values. 
The following main reasons could explain this quantitative agreement of $U_{\max }\left(T_{\mathrm{gr}}\right)$, which is much better than that observed for the $I_{\max }\left(T_{\mathrm{gr}}\right)$ :

(i) For realistic $T_{\mathrm{gr}}, T_{\mathrm{max}}^{U} / T_{\mathrm{m}}$ are located far above $T_{\mathrm{gr}}$ (see Fig. 3); hence, the use of the Stokes-Einstein equation to account for the diffusion of the building molecular units that control crystal growth is correct, while, at typical temperatures of nucleation rate maxima, which are located near the glass transition temperature, the validity of the Stokes-Einstein equation is still a matter of controversy (for instance see Ref. [14]).

(ii) In contrast to crystal nucleation, for which the crystal/liquid surface energy, $\sigma$, and thermodynamic driving force, $\Delta G$, determine the value of the thermodynamic barrier for nucleation and strongly affect calculations of nucleation rates, the roles of $\sigma$ and $\Delta G$ in the screw dislocation growth model and normal growth model are quite weak (see Eqs. (1), (3) and (12)). Hence, variations in $\sigma$ and $\Delta G$ between different glasses do not lead to significant changes in crystal growth rates, as they do in the case of crystal nucleation rates.

(iii) The screw dislocation growth model is a good approximation to describe crystal growth rates in most silicate glasses.

It should be noted that the facts mentioned under item (ii) are also responsible for the strong dependence of $I_{\max }$ on $T_{\mathrm{gr}}$ relative to a weak increase of $U_{\max }$ with decreasing $T_{\mathrm{gr}}$. For instance, considering silicate glasses, $I_{\max }$ increases by about 12 orders of magnitude for a 0.1 change in $T_{\mathrm{gr}}$, while $U_{\max }$ increases by only about 2.6 orders of magnitude.

\section{Conclusions}

In this paper we demonstrate that the maximum crystal growth rates of silicate glasses decrease with the reduced glass transition temperature. We use the most common crystal growth model - screw dislocation growth - to calculate and compare maximum experimental growth rates with theoretical predictions. Despite the several assumptions made in the calculations, there is a good agreement between the experimental data and the calculated curves, not only in the dependence of $U_{\max }\left(T_{\mathrm{gr}}\right)$, but also in the magnitudes of $U_{\max }$. Reasonable agreement was also attained between the experimental and calculated temperatures of crystal growth maxima, $T_{\max }^{U}$. These findings indirectly indicate that the screw dislocation growth model is a good approximation to describe crystal growth in silicate glasses.

\section{References}

[1] W. Holland, G. Beall, Glass Ceramic Technology, The American Ceramic Society, Westerville, OH, 2002.

[2] A. Zakery, S.R. Elliott, J. Non-Cryst. Solids 330 (2003) 1.

[3] J. Lucas, paper presented at A celebration to the life of Michael Weinberg - A Symposium, Tucson, AZ, October 2003.

[4] J.H. Perepezko, W.S. Tong, Philos. Trans. Roy. Soc. London A 361 (2003) 447.

[5] K.F. Kelton, Solid State Phys. 45 (1991) 75.

[6] V.M. Fokin, E.D. Zanotto, J. Schmelzer, J. Non-Cryst. Solids 321 (2003) 52.

[7] V.M. Fokin, unpublished result.

[8] Z.P. Lu, Y. Li, S.C. Ng, J. Non-Cryst. Solids 270 (2002) 103.

[9] D.R. Uhlmann, Crystal growth in glass forming systems: a ten years perspective, Advances in Ceramics, Nucleation and crystallization in glasses, vol. 4, American Ceramic Society, Ohio, 1982.

[10] K.A. Jackson, The Nature of Solid Liquid Interfaces, Dover, New York, 1958.

[11] N.D. Mora, E.D. Zanotto, V.M. Fokin, Phys. Chem. Glasses 39 (1998) 91.

[12] I. Gutzow, J. Schmelzer, The Vitreous State, Springer, Berlin, 1995.

[13] V.N. Filipovich, Glass Phys. Chem. 1 (1975) 426.

[14] J.W.P. Schmelzer, O.V. Potapov, V.M. Fokin, R. Müller, S. Reinsch, J. Non-Cryst. Solids 333 (2004) 150.

[15] K. Matusita, M. Tashiro, Yogyo-Kyokai-Shi 81 (1973) 500.

[16] G.S. Meiling, D.R. Uhlmann, Phys. Chem. Glasses 8 (1967) 62.

[17] M.L.F. Nascimento, E.B. Ferreira, E.D. Zanotto, J. Chem. Phys. 121 (2004) 8924.

[18] M.L.F. Nascimento, PhD thesis. Federal University of São Carlos, São Paulo, 2004 (in Portuguese).

[19] S. Reinsch, Dr Ing. thesis, Technical University of Berlin, Berlin, 2001, (in German).

[20] F.E. Wagstaff, J. Am. Ceram. Soc. 52 (1969) 650.

[21] E.V. Shkol'nikov, Fiz. Khim. Stekla 6 (1980) 153.

[22] M.L.F. Nascimento, E.D. Zanotto, Acta Materialia, in preparation.

[23] A. Leontjeva, Acta Physicochim. URSS 14 (1941) 245.

[24] Z. Qian, T.L. Tolt, A.R. Cooper, J. Am. Ceram. Soc. 70 (1987) 48.

[25] N.A. Ghoneim, H.A. El-Batal, A.A. Ahmed, F.A. Khalifa, Trans. J. Br. Ceram. Soc. 78 (1979) 15.

[26] C.A. Handwerker, P.I.K. Onorato, D. Uhlmann, in: R.B. Merrill, J.J. Papike (Eds.), Mare Crisium: The View from Luna, vol. 24, Pergamon, 1978, p. 483.

[27] A. Karamanov, M. Pelino, M. Salvo, I. Metekovits, J. Euro. Ceram. Soc. 23 (2003) 1609.

[28] T.S. Neiman, H. Yinnon, D.R. Uhlmann, J. Non-Cryst. Solids 48 (1982) 393.

[29] A.J. Milne, J. Soc. Glass Technol. 36 (1952) 275.

[30] C. Paucar, PhD thesis, Instituto de Ceramica y Vidrio, Madrid, 2005 (in Spanish).

[31] Sciglass ${ }^{\circledR}$ database. http://www.esm-software.com/sciglass. 